Religiöse und sozialpolitische Tendenz 



\section{Religiöser Antimodernismus und ökonomische Modernität}

\section{Der Regensburger Verlag Pustet und die katholische populäre Publizistik im mittleren 19. Jahrhundert}

Die Simultaneität von umfassender Modernisierung der politischen, wirtschaftlichen und gesellschaftlichen Verhältnisse und offenkundiger Hinwendung zu einer als Legitimationsbasis antimoderner Konzepte und Praktiken fungierenden Vergangenheit ist in der Historiographie zum 19. Jahrhundert längst als Konstituens einer Epoche erkannt worden, die auch und gerade in Deutschland durch fundamentale strukturelle Umbrüche gekennzeichnet war und zugleich Formen einer Traditionsbindung Raum bot, welche die mit diesen Umbrüchen einhergehenden Verlusterfahrungen zu entschärfen geeignet erschienen. ${ }^{1}$ Besonders auffällig manifestiert sich das Spannungsfeld von Fortschrittsbeschleunigung und Rückwärtsorientierung im Bereich der Religion, deren Geltungsmacht bereits in der ersten Hälfte des 19. Jahrhunderts zunahm und die in der Folge, wie nicht zuletzt die politisch-konfessionellen Verwerfungen im Kontext des Kulturkampfs verdeutlichen, zu einem wesentlichen Katalysator gesellschaftlicher Mobilisierung avancierte. Auf die Bismarck'sche Politik und die dadurch geförderte Wahrnehmung preußisch-protestantischer Dominanz antwortete die katholische Kirche mit einer Gegenoffensive, als deren wirksamstes Instrument sich neben der deutschen Zentrumspartei als Repräsentantin des politischen Katholizismus und einer wachsenden Zahl kirchlicher Gruppierungen eine auf Massenwirksamkeit bedachte Publizistik erweisen sollte, die allerdings in der Forschung bislang kaum Aufmerksamkeit gefunden hat. ${ }^{2}$ Deren Bedeutung für die konfessionelle Identitätsstiftung innerhalb der katholischen Bevölkerung ist zwar bemerkt worden, ${ }^{3}$

1 Vgl. z. B. David Blackbourn: The Long Nineteenth Century. A History of Germany, 1780-1918. New York/Oxford 1998, S. 270-310.

2 Vgl. immerhin die ältere Studie von Josef Lange: Die Stellung der überregionalen katholischen deutschen Tagespresse zum Kulturkampf in Preußen (1871-1878). Bern/Frankfurt a.M. 1974 (Europäische Hochschulschriften 40). Zur (nicht nur katholischen) Kirchenpresse generell vgl. Michael Schmolke: Kirchenpresse. In: Andreas Vogel/Christina Holtz-Bacha (Hg.): Zeitschriften und Zeitschriftenforschung. Wiesbaden 2002 (Publizistik. Sonderheft 3/2002), S. 126-146.

3 So etwa Christopher Clark: Der neue Katholizismus und der europäische Kulturkampf. In: C. C./ Wolfram Kaiser (Hg.): Kulturkampf in Europa im 19. Jahrhundert. Leipzig 2003, S. 14-37, hier S. 21-28. 
die systematische Befassung mit den verschiedenen Formen maßgeblich von kirchlichen bzw. kirchennahen Institutionen und Akteuren gesteuerter publizistischer Initiativen steht allerdings noch aus. Dies gilt nicht nur mit Blick auf die Zentrumspresse, sondern auch und vor allem für die in bemerkenswert hoher Auflage erschienenen populären Periodika, allen voran die unterhaltenden Familienzeitschriften und Kalender katholischer Prägung. Letztere bilden die empirische Basis meiner folgenden Ausführungen, deren Ziel darin besteht, die Signifikanz eines Mediums herauszustellen, dessen Beitrag zur ,Romanisierung' des deutschen Katholizismus, ${ }^{4}$ zur Integration katholischer Milieus ${ }^{5}$ und zur Erneuerung einer Volksfrömmigkeit römisch-katholischer Observanz kaum zu überschätzen ist. Ich konzentriere mich dabei auf den Regensburger Marien-Kalender, der sich nicht nur wegen seiner weiten Verbreitung, sondern auch aufgrund seiner charakteristischen Kombination von Traditionsbezug und Innovationsfreude für eine exemplarische Analyse anbietet. Auffällig ist nämlich, dass der Regensburger Marien-Kalender das eingangs angesprochene Spannungsfeld in doppelter Hinsicht auslotet: Er fügt sich ein in die lange Reihe populärer Kalender und greift auf deren gattungsspezifische Merkmale zurück, zugleich jedoch aktualisiert er das Medium, das er verkörpert, um es jenen Zielsetzungen dienstbar zu machen, welche seine Existenz begründen. Diese Zielsetzungen wiederum stehen in Einklang mit zeitgenössischen Bestrebungen, vor den Verirrungen einer als feindlich wahrgenommenen Moderne zu warnen und tradierten religiösen Konzepten und Praktiken innerhalb katholischer Milieus stärkere Resonanz zu verschaffen. Die Art und Weise allerdings, wie ein derartiges, sich dezidiert antimodernistisch gebärdendes Programm im Regensburger Marien-Kalender vermittelt wird, ist durchaus innovativ und erhellt den für die publizistische Produktion katholischer Verlage nicht ungewöhnlichen, nur scheinbaren Widerspruch zwischen religiös bedingtem Konservatismus einerseits und zeitgemäßem Geschäftsgebaren andererseits. Der Regensburger Marien-Kalender erweist sich so als ein zentrales Vehikel für die Popularisierung ultramontaner Katholizität und als Beleg für die zukunftsorientierten, die Chancen eines sich dynamisch entwickelnden literarisch-publizistischen Markts professionell nutzenden Strategien seiner Verleger Friedrich und Karl Pustet. Der hier angedeutete Antagonismus steht im Zentrum meiner Darlegungen, in denen ich zunächst den

4 Vgl. Clark: Der neue Katholizismus (Anm. 3), S. 18.

5 Zum Begriff des ,Milieus‘ als einer Kategorie zur Beschreibung konfessionell einheitlicher Kollektive vgl. Olaf Blaschke/Frank-Michael Kuhlemann: Religion in Geschichte und Gesellschaft. Sozialhistorische Perspektiven für die vergleichende Erforschung religiöser Mentalitäten und Milieus. In: O. B./F.-M. K. (Hg.): Religion im Kaiserreich. Milieus - Mentalitäten - Krisen. Gütersloh 1996 (Religiöse Kulturen der Moderne 2), S. 7-56, hier S. 24-56. 
für das 19. Jahrhundert konstitutiven Geltungsgewinn einer - wie die mit dem Kulturkampf einhergehenden Konflikte verdeutlichen - dezidiert politisch aufgeladenen Religiosität herausstelle, der der Typus des katholischen Kalenders seine Genese verdankt, bevor ich in einem zweiten Schritt den Regensburger Marien-Kalender einer Analyse unterziehe, die dessen theologisch und klerikal legitimierten Konservatismus konkretisiert. Abschließend sollen dann einige jener Strategien zur Sprache kommen, mittels derer es dem Unternehmen Pustet gelang, sich als einer der erfolgreichsten Repräsentanten des katholischen Verlagswesens zu etablieren, eines Verlagswesens, in dem die hier interessierende Dichotomie von Traditionsbindung und Modernität aus naheliegenden Gründen besonders evident erscheint.

Die aus medienhistorischer Sicht folgenreichste Entwicklung im mittleren 19. Jahrhundert stellt zweifellos die Herausbildung des modernen publizistischliterarischen Massenmarkts dar. ${ }^{6}$ Sie verdankt sich einer Reihe von Faktoren, die hier nur angedeutet werden können: Von zentraler Bedeutung sind zum einen die sich im Lauf des 19. Jahrhunderts in ganz Europa wandelnden Bildungsvoraussetzungen breiterer Bevölkerungsschichten. Insbesondere die Einführung eines obligatorischen Schulunterrichts begünstigte die flächendeckende Alphabetisierung auch im deutschsprachigen Raum und markierte den Beginn dessen, was in der Forschung bisweilen als ,zweite Leserevolution' beschrieben wurde. ${ }^{7}$ Die durch die Ausweitung der Lesefähigkeit bewirkte rapide Steigerung der Nachfrage nach Gedrucktem wiederum zwang den Buchhandel, die Produktion und Distribution zu professionalisieren, und tatsächlich gelang es durch technische Innovationen im Bereich des Buchdrucks, der Papierherstellung und der Illustration die Herstellung von Druckerzeugnissen $\mathrm{zu}$ beschleunigen und $\mathrm{zu}$ verbilligen und deren Vertrieb zu optimieren. Damit gewannen auch die in finanziell beschränkten Verhältnissen lebenden Angehörigen unterer Schichten als Rezipienten an Bedeutung, die - nicht zuletzt aufgrund der sich seit den 1850er Jahren abzeichnenden, mit einer Intensivierung und Demokratisierung des politischen Diskurses, gesteigerter wirtschaftlicher Dynamik und sozialer Mobilität sowie mit

6 Vgl. hierzu Jürgen Wilke: Grundzüge der Medien- und Kommunikationsgeschichte. Von den Anfängen bis ins 20. Jahrhundert. Köln/Weimar/Wien 2000, S. 155-302, der in diesem Zusammenhang von einer „Entfesselung der Massenkommunikation“ spricht (S. 155).

7 Vgl. Ute Schneider: Leser/in. In: Friedrich Jaeger u. a. (Hg.): Enzyklopädie der Neuzeit, Bd. 7. Stuttgart/Weimar 2008, Sp. 850-853, hier Sp. 853. 
neuen Denk- und Lebensstilen einhergehenden gesellschaftlichen Umwälzungen - immer häufiger als Käufer gedruckter Medien in Erscheinung treten. Der publizistisch-literarische Markt reagierte auf diese Situation, indem er einerseits mit geradezu atemberaubender Geschwindigkeit expandierte und sich andererseits den heterogenen Lesebedürfnissen eines zunehmend dispersen Publikums anpasste. Kennzeichnend für das Kommunikationssystem um 1850 erscheint demnach nicht nur das durch den stetig erhöhten Ausstoß an publizistischen und literarischen Veröffentlichungen bewirkte quantitative Wachstum, sondern auch ein qualitativer Wandel, der zunächst weniger durch die Implementierung neuer, als vielmehr durch die Modifikation und Diversifikation traditioneller Medien charakterisiert ist.

$\mathrm{Zu}$ jenen traditionellen Medien, deren Form und Funktion im Lauf des 19. Jahrhunderts signifikante Änderungen erfuhren, gehört auch der gedruckte Kalender, dessen Anfänge in die Frühzeit des Buchdrucks zurückreichen, der während des 16. und 17. Jahrhunderts zu der für ihn typischen Form fand und der im Zuge der Aufklärung zu einem der populärsten und am weitesten verbreiteten Druckerzeugnisse avancierte. ${ }^{8}$ In welchem Maße der Kalender einer grundlegenden Transformation unterlag, offenbart die Kalenderproduktion seit dem 18. Jahrhundert. Das bereits im Zuge der Aufklärung signifikanten Modifikationen unterworfene Medium, wandelte sich im 19. Jahrhundert noch einmal, um sich angesichts geänderter Anforderungen am Markt behaupten zu können. Wichtigster Indikator für den hier behaupteten Wandlungsprozess ist die von mir bereits angesprochene, für die Publizistik des 19. Jahrhunderts generell zu beobachtende Diversifizierung der Produktion. Den meist regional verankerten, sich an breite ländliche und städtische Leserschichten richtenden traditionellen Kalendern erwuchs Konkurrenz durch eine stetig steigende Zahl spezialisierter Kalender, die sich an ausgewählte Berufsgruppen wandten oder spezifische religiöse und ideologische Positionen vertraten. Auf prägnante Weise beschrieben hat dies 1852 der Kulturhistoriker Wilhelm Heinrich Riehl:

Wir haben jetzt Volkskalender der politischen Parteien, mehr noch der kirchlichen; die Regierungen lassen Kalender schreiben, weil sie wissen, daß sie mit ihren officiellen Zeitungen niemals bis zu den Bauern durchdringen können, und die Opposition säumt dann

8 Vgl. Alfred Messerli: Kalender, 7: Publizistisches Medium. In: Friedrich Jaeger u.a. (Hg.): Enzyklopädie der Neuzeit, Bd. 6. Stuttgart/Weimar 2007, Sp. 279-282; Jan Knopf: Kalender. In: Ernst Fischer/Wilhelm Haefs/York-Gothart Mix (Hg.): Von Almanach bis Zeitung. Ein Handbuch der Medien in Deutschland 1700-1800. München 1999, S. 121-136 sowie Ursula BrunoldBigler: Kalender, Kalendergeschichte. In: Kurt Ranke u.a. (Hg.): Enzyklopädie des Märchens. Handwörterbuch zur historischen und vergleichenden Erzählforschung, Bd. 7. Berlin 1993, Sp. 861 878. 
auch nicht, ihrerseits mit Kalendern ins Feld zu rücken. Nationalistische und orthodoxe Kalender werben um Land und Leute; protestantische Traktatengesellschaften lassen aus ihren Traktätchen Volkskalender zusammenstellen, und katholische Kleriker streiten in Kalendern ,für Zeit und Ewigkeit‘ mit dem Eifer und der Derbheit mittelalterlicher Predigermönche für ihren Kirchenglauben. Man schreibt Bauernkalender, die niemals ein Bauer liest, um Dorfgeschichten zu ediren, und illustrirte Kalender welche Pfennigmagazin und Conversationslexikon zugleich ersetzen sollen; dazu landwirthschaftliche Kalender, statistische Geschäftskalender, Jugendkalender und Gott weiß was sonst noch. ${ }^{9}$

Wie lebendig und vielfältig sich die ,Kalenderlandschaft' noch in der zweiten Hälfte des 19. Jahrhunderts präsentierte, bestätigt auch der Schweizer Theologe August Steiger, der in einem anlässlich der Versammlung der appenzellischen gemeinnützigen Gesellschaft vom 7. September 1885 gehaltenen Vortrag von der „ganz enormen Verbreitung“ der Kalender spricht und deren Bedeutung als "hochwichtige[n] Volksschrift" hervorhebt. ${ }^{10}$

Es ist kein Zufall, dass Riehl in seiner Aufzählung die konfessionell gebundenen Kalender wiederholt erwähnt und Steiger zu berichten weiß, dass im Kanton Appenzell Innerrhoden vor allem katholische Kalender, namentlich der Einsiedler-Kalender und der Regensburger Marien-Kalender, weite Verbreitung gefunden hätten. ${ }^{11}$ Wie Ursula Brunold-Bigler in ihrer Studie über Die religiösen Volkskalender in der Schweiz im 19. Jahrhundert nachweisen konnte, kam es auf dem Gebiet der Eidgenossenschaft bereits in der ersten Hälfte des 19. Jahrhunderts $\mathrm{zu}$ zahlreichen Gründungen vor allem evangelischer Kalender, bevor in der zweiten Hälfte des 19. Jahrhunderts katholische Verlagshäuser die religiös orientierte Kalenderproduktion zu dominieren begannen. ${ }^{12}$ Innerhalb der ,Kalenderlandschaft' des 19. Jahrhunderts bilden die religiösen Kalender denn auch einen - nicht nur in quantitativer Hinsicht - relevanten, bislang allerdings so gut wie gar nicht erforschten Subtypus. Das offenkundige wissenschaftliche Desinteresse an religiösen Kalendern ist nicht allein der Tatsache geschuldet, dass die Kalender aus der zweiten Hälfte des 19. Jahrhunderts als Gegenstand akademischer Studien generell eine allenfalls marginale Rolle spielen, sie dürfte auch mit der in der Forschung lange perpetuierten Auffassung zusammenhängen, der Geltungsverlust religiöser Bindungen bilde eine der wesentlichen Epochensi-

9 Wilhelm Heinrich Riehl: Volkskalender im 18. Jahrhundert (1852). In: W. H. R: Culturstudien aus drei Jahrhunderten. Zweiter, unveränderter Abdruck. Stuttgart 1859, S. 38-56, hier S. 40. 10 A[ugust] Steiger: Was unser Volk liest. In: Appenzellische Jahrbücher 17 (1886), S. 18-44, hier S. $33 \mathrm{f}$.

11 Steiger: Was unser Volk liest (Anm. 10), S. 33.

12 Ursula Brunold-Bigler: Die religiösen Volkskalender der Schweiz im 19. Jahrhundert. Basel 1982 (Beiträge zur Volkskunde 2). 
gnaturen der Moderne. ${ }^{13}$ Im Kontext einer derartigen Perzeption gerieten all jene Phänomene aus dem Blick, welche das Postulat eines in der Aufklärung einsetzenden Verfalls religiöser Werte und Praktiken konterkarieren. Insofern ist es zu begrüßen, dass das Säkularisierungsparadigma gegen Ende des vergangenen Jahrtausends verstärkt in die Kritik geraten ist und die prägende Kraft religiöser Vorstellungen in Politik, Wirtschaft, Gesellschaft und Kultur gerade im 19. Jahrhundert erneut in den Fokus wissenschaftlicher Analyse rückte. ${ }^{14}$ So hat der Historiker Olaf Blaschke in einem vielbeachteten Aufsatz die These vertreten, Religion sei im 19. Jahrhundert keinesfalls einem „kontinuierlichen Auszehrungsprozeß“ unterworfen gewesen, sondern habe vielmehr eine „ungeahnte Renaissance“ erlebt, die es erlaube, die Jahrzehnte zwischen Vormärz und dem Wirtschaftswunder der 1950er Jahre als zweites Konfessionelles Zeitalter zu bezeichnen. ${ }^{15}$ Blaschkes durchaus kontrovers diskutierter ${ }^{16}$ Versuch, der Religion den ihr im 19. Jahrhundert als einer zentralen Deutungs- und Gestaltungsmacht gebührenden Platz einzuräumen, ist in unserem Zusammenhang insofern hilfreich, als er es ermöglicht, einige historische Rahmenbedingungen, innerhalb deren religiöse Kalender Bedeutung erlangten, in Erinnerung zu rufen. Erhellend scheinen mir hier insbesondere jene Entwicklungen, die Blaschke in Analogie

13 Vgl. hierzu u. a. Hartmut Lehmann: Säkularisierung. Der europäische Sonderweg in Sachen Religion. Göttingen 2004 (Bausteine zu einer europäischen Religionsgeschichte im Zeitalter der Säkularisierung 5); Detlef Pollack: Säkularisierung - ein moderner Mythos? Studien zum religiösen Wandel in Deutschland. Tübingen 2003; Hermann Lübbe: Säkularisierung. Geschichte eines ideenpolitischen Begriffs. Freiburg i. Br. ${ }^{3} 2003$.

14 Vgl. z. B. Gerhard Besier: Kirche, Politik und Gesellschaft im 19. Jahrhundert. München 1998 (Enzyklopädie deutscher Geschichte 48), oder Thomas Nipperdey: Religion im Umbruch. Deutschland 1870-1918. München 1988.

15 Olaf Blaschke: Das 19. Jahrhundert: Ein Zweites Konfessionelles Zeitalter? In: Geschichte und Gesellschaft 26 (2000), S. 38 - 75, hier S. 40. Blaschke hat seine These in der Folge in weiteren Beiträgen empirisch fundiert und differenziert; vgl. z. B. Olaf Blaschke: Der „Dämon des Konfessionalismus“. Einführende Überlegungen. In: O. B. (Hg.): Konfessionen im Konflikt. Deutschland zwischen 1800 und 1970: ein zweites konfessionelles Zeitalter. Göttingen 2002, S. 13-69, oder Olaf Blaschke: Abschied von der Säkularisierungslegende. Daten zur Karrierekurve der Religion (1800 - 1970) im zweiten konfessionellen Zeitalter: eine Parabel. In: zeitenblicke 5 (2006), Nr. 1. URL: http://www.zeitenblicke.de/2006/1/Blaschke/index_html (letzter Zugriff 19. März 2014).

16 Vgl. etwa Carsten Kretschmann/Henning Pahl: Ein „Zweites Konfessionelles Zeitalter“? Vom Nutzen und Nachteil einer neuen Epochensignatur. In: Historische Zeitschrift 276 (2003), S. 369 392. Differenzierter zuletzt Winfried Müller: Nach der Aufklärung - die These vom 19. Jahrhundert als zweitem konfessionellen Zeitalter. In: Ulrich Rosseaux/Gerhard Poppe (Hg.): Konfession und Konflikt. Religiöse Pluralisierung in Sachsen im 18. und 19. Jahrhundert. Münster 2012, S. 221 232. 
setzt zu den konfessionellen Dynamiken des als erstes Konfessionelles Zeitalter in die Geschichte eingegangenen langen 16. Jahrhunderts: Er nennt in diesem Zusammenhang erstens die für das 19. Jahrhundert kennzeichnende ,Rechristianisierung، im Sinne einer „religiösen Rückbesinnung, Klerikalisierung und kirchlichen Konsolidierung. “17 Auf die Erschütterung tradierter religiöser Ordnungen etwa durch den Rationalismus der Aufklärung oder die Aufhebung kirchlicher Institutionen im Zuge der Säkularisation von 1803 hätten nämlich sowohl Protestanten als auch Katholiken mit einer verstärkten Hinwendung zu einer zunehmend konfessionell gefärbten Spiritualität reagiert. Letztere ist nur ein Beispiel für jene sämtliche Lebensbereiche durchdringende ,Konfessionalisierung“, die Blaschke als zweite wesentliche Epochentendenz hervorhebt. Ihren Ausdruck findet diese Konfessionalisierung in der Klerikalisierung, der Zentralisierung und einer verstärkten Sozialreglementierung innerhalb der jeweiligen konfessionellen Sphären. Steht der Begriff der ,Klerikalisierung“ sowohl für die „Professionalisierung der Pfarrerschaft“ als auch für deren „Kompetenz- und Machtausweitung“, ${ }^{18}$ so bezeichnet ,Zentralisierung، den insbesondere im Bereich des römischen Katholizismus zu beobachtenden Gewinn an institutioneller Macht und das Bestreben, die Frömmigkeit der Gläubigen mittels kirchlicher Institutionen zentral zu steuern. ${ }^{19}$,Sozialreglementierung' wiederum steht für die Wiederbelebung tradierter bzw. die Implementierung neuer Formen kirchlicher Kontrolle wie beispielsweise Visitationen, Zensurmaßnahmen oder die Überprüfung religiöser Praktiken durch Beichtzähler und die Einführung von Kommunionszetteln. ${ }^{20}$ Von der durch die genannten Prozesse bewirkten intrakonfessionellen Konsolidierung zu unterscheiden ist drittens das, was Blaschke als ,äußere Konfessionalisierung beschreibt, d.h. die Polemisierung, die Polarisierung und die Politisierung der Interaktion zwischen den großen Konfessionskirchen und ihren Anhängern, die sich in zunehmendem Maße als Antagonisten verstanden. Manifestiert sich die Polemisierung vor allem in publizistischen Invektiven und in einer sich bisweilen äußerst aggressiv gebärdenden Rhetorik, lässt sich die Polarisierung an den zahlreichen Debatten etwa zur ,Mischehenfrage“ oder zu den Konfessionsschulen ablesen. Die Politisierung der Religion belegen nicht nur jene politischen Parteien, die, wie das katholische Zentrum oder die protestantisch dominierte Nationalliberale Partei, die Interessen spezifischer Konfessionsgruppen vertraten, sondern auch und besonders spektakulär die Auseinandersetzungen zwischen dem

17 Blaschke: Das 19. Jahrhundert (Anm. 15), S. 60.

18 Blaschke: Das 19. Jahrhundert (Anm. 15), S. 61.

19 Blaschke: Das 19. Jahrhundert (Anm. 15), S. 62.

20 Blaschke: Das 19. Jahrhundert (Anm. 15), S. 62 f. 
preußischen Staat und der katholischen Kirche im Kontext des Kulturkampfs. ${ }^{21}$ Diese konflikthafte religiöse Lage nun begünstigte viertens Formen einer konfessionsgebundenen Vergesellschaftung und damit das soziale Auseinanderdriften von Protestanten und Katholiken, die vermehrt in klar voneinander abgegrenzten Makromilieus mit jeweils eigenen Institutionen verkehrten. Protestanten und Katholiken wählten nicht nur unterschiedliche Parteien, sie verfügten über eigene Vereine und Presseorgane und sie legitimierten ihre Denk- und Handlungsweisen mit je eigenen Weltdeutungsmustern. ${ }^{22}$ Der für das 19. Jahrhundert konstitutive konfessionelle Gegensatz äußert sich schließlich und fünftens in einem Utopismus, der mit der Vision einer rein katholischen bzw. protestantischen Welt einherging. Dass die Konversion zu einem hochsensiblen Thema avancierte und insbesondere in der katholischen Publizistik breiten Raum einnehmen konnte, vermag vor diesem Hintergrund kaum zu überraschen. ${ }^{23}$

Auch wer der durch die Formel des ,Zweiten Konfessionellen Zeitalters‘ implizierten Analogiebildung zwischen 16. und 19. Jahrhundert nicht in allen Punkten folgen mag, wird konzedieren müssen, dass Blaschke ein taugliches Beschreibungsmodell liefert - nicht nur für die Geltungsmacht der Religion im 19. Jahrhundert, sondern darüber hinaus für die den uns interessierenden Zeitraum bestimmenden konfessionspolitischen Konstellationen, die im seit den frühen 1870er Jahren eskalierenden Kulturkampf ihren Kulminationspunkt erlebten. In Anbetracht der Tatsache, dass die bemerkenswerte Dynamik der katholischen Publizistik generell und der religiösen Kalender im Besonderen sich nicht zuletzt jenen Verwerfungen verdankt, die sich mit dem Begriff des ,Kulturkampfs' verbinden, müssen jene Problemfelder, die auch und gerade in jenem Kalender, dem ich mich im Folgenden zuwenden werde, ihren Widerhall fanden, kurz beleuchtet werden. ,Kulturkampf‘ bezeichnet die bereits im Kontext des Aufstiegs des politischen Liberalismus virulenten, sich in der zweiten Hälfte des 19. Jahrhunderts verschärfenden Auseinandersetzungen zwischen den sich etablierenden modernen europäischen Staaten und dem am Primat von Kirche und Religion festhaltenden römischen Katholizismus. ${ }^{24}$ Dabei betraf der um das Ver-

21 Blaschke: Das 19. Jahrhundert (Anm. 15), S. 63-67.

22 Blaschke: Das 19. Jahrhundert (Anm. 15), S. $67 \mathrm{ff}$.

23 Blaschke: Das 19. Jahrhundert (Anm. 15), S. $69 \mathrm{f}$.

24 Zum Kulturkampf insbesondere in Deutschland vgl. u. a. Manuel Borutta: Antikatholizismus. Deutschland und Italien im Zeitalter der europäischen Kulturkämpfe. Göttingen 2010 (Bürgertum 7); Jürgen Strötz: Der Katholizismus im deutschen Kaiserreich 1871-1918. Strukturen eines problematischen Verhältnisses zwischen Widerstand und Integration, Bd. 1: Reichsgründung und Kulturkampf (1871-1890). Hamburg 2005 (Studien zur Religionspädagogik und Pastoralgeschichte 6); Michael B. Gross: The War against Catholicism. Liberalism and the Anti-Catholic 
hältnis von Staat und Kirche zentrierte Konflikt keinesfalls nur die Institutionen der beteiligten Akteure, er manifestierte sich vielmehr, wie Winfried Becker jüngst betont hat, als „Zusammenstoß zweier sich gleichsam gegenseitig konstituierender kultureller Welten, ,Lebensformen“ oder Zivilisationen“ und zwar „eines national-etatistischen, für sich allein Modernität und Fortschritt reklamierenden Kultur-Liberalismus“ einerseits und „einer mehr den traditionellen Normen und Werten verpflichteten katholischen Kultur“ andererseits. ${ }^{25}$ Der Kulturkampf erweist sich so als eine nahezu alle Bereiche des sozialen Lebens tangierende Konfrontation zwischen ,Modernisten' und ,Traditionalisten', die die europäischen Gesellschaften auf Jahrzehnte hinaus polarisierte. Als Protagonisten traten denn auch nicht nur die Repräsentanten der staatlichen und kirchlichen Hierarchie in Erscheinung; eine entscheidende Rolle spielten darüber hinaus Parteien, Vereine und die Presse. Sie waren es, welche die Anliegen der Kontrahenten zu popularisieren versuchten und sich um die Mobilisierung einer Massenbasis bemühten, die den Forderungen liberaler bzw. ultramontaner Kräfte zum Durchbruch verhelfen sollte. Dass die Bestrebungen des politischen Katholizismus, den Rückhalt der Massen zu gewinnen, sich als besonders erfolgreich erwiesen, dürfte nicht zuletzt der Bismarck'schen Politik geschuldet sein, die ab den frühen 1870er Jahren darauf zielte, den Einfluss der römisch-katholischen Kirche sowohl in Preußen als auch auf Reichsebene zurückzudrängen. Die in diesem Zusammenhang erlassenen Gesetze und Maßnahmen, die wie etwa die 1872 erfolgte Aufhebung der geistlichen Schulaufsicht in Preußen und die drei Jahre später dekretierte Ablösung der letzten verbliebenen Ordensschulen durch staatliche Erziehungseinrichtungen oder die Einführung der obligatorischen Zivilehe 1874/75 einen Eingriff in zentrale Befugnisse der Kirche darstellten, konnten von ultramontanen Propagandisten als Indikatoren für die bedrängte Lage, in der sich die katholische Minderheit im noch jungen Kaiserreich befand, ins Feld geführt werden. Der den Geistlichen durch den ,Kanzelparagraphen“ von 1871 verpasste Maulkorb, das Jesuitengesetz von 1872, der sich in den Maigesetzen von 1873 manifestierende Anspruch des preußischen Staates, die Ausbildung und Einstellung der Geistlichen zu kontrollieren, das 1875 verabschiedete ,Brotkorbgesetz', das der Kirche die staatlichen Zuwendungen entzog, sowie die im selben Jahr erlassenen Bestimmungen, die zur Aufhebung der meisten Orden in Preußen führten, bestärkten die Vorstellung einer illegitimer staatlicher Verfolgung aus-

Imagination in Nineteenth-Century Germany. Ann Arbor 2004 (Social History, Popular Culture, and Politics in Germany); Clark/Kaiser (Hg.): Kulturkampf in Europa (Anm. 3).

25 Winfried Becker: Der Kulturkampf in Preußen und in Bayern. Eine vergleichende Betrachtung. In: Jörg Zedler (Hg.): Der Heilige Stuhl in den internationalen Beziehungen 1870 - 1939. München 2010 (Spreti-Studien 2), S. 51-91, hier S. 51. 
gesetzten Kirche, eine Vorstellung, die durch den Anschluss weiter Teile des Kirchenstaats an das Königreich Italien 1860, vor allem jedoch durch die Annexion Roms durch italienische Truppen im Sommer 1870 und den damit verbundenen Verlust der weltlichen Herrschaftsrechte des Papstes zusätzliche Nahrung erhielt. Angesichts der als äußerst prekär empfundenen Situation traten die Interessensgegensätze zwischen liberalen und konservativen Katholiken in den Hintergrund, die im Streit um das Unfehlbarkeitsdogma unterlegenen Verfechter eines nicht-ultramontanen Katholizismus verloren an Bedeutung, ${ }^{26}$ die Einheit des Kirchenvolkes galt nun als oberstes zu verteidigendes Ziel.

Die Wahlerfolge der Zentrumspartei, der zügige Ausbau des konfessionellen Vereins- und Verbandswesens und der unübersehbare Aufschwung der katholischen Presse machen deutlich, in welchem Maße es in den 1870er Jahren gelungen ist, die katholische Bevölkerung unter der Führung des Episkopats zu vereinigen und sie zu einer schichtenübergreifenden, hinsichtlich ihrer konfessionellen und politischen Identität tendenziell geschlossenen Solidargemeinschaft zu formen. ${ }^{27}$

Wesentlichen Anteil an diesem Prozess hatten nicht so sehr die hinsichtlich ihrer politischen Spannbreite einigermaßen heterogenen katholischen Zeitungen, deren Zahl sich allein zwischen 1871 und 1881 fast verdoppelte, ${ }^{28}$ sondern vor allem jene Medien, die auch die traditionell wenig politisierten bäuerlichen und kleinbürgerlichen Schichten zu erreichen vermochten und deren Reichweite die der kaum je überregionale Ausstrahlung erreichenden Zeitungen bisweilen bei weitem übertraf. $\mathrm{Zu}$ diesen Medien - und damit bin ich wieder bei meinem Ausgangspunkt angelangt - zählen auch und gerade die teilweise in hoher Auflage erscheinenden, oft überregional verbreiteten katholischen Kalender, etwa der Einsiedler Marien-Kalender, ${ }^{29}$ der Eichsfelder Marien-Kalender ${ }^{30}$ oder der Regensburger Marien-Kalender, dem im Folgenden meine Aufmerksamkeit gilt.

26 Vgl. Thomas Nipperdey: Deutsche Geschichte 1866 - 1918, Bd. 1: Arbeitswelt und Bürgergeist. München 1994, S. 428-431.

27 Vgl. Rudolf Morsey: Der Kulturkampf. Bismarcks Präventivkrieg gegen das Zentrum und die katholische Kirche. In: Manfred Weitlauff (Hg.): Kirche im 19. Jahrhundert. Regensburg 1998 (Themen der Katholischen Akademie in Bayern), S. 163-185, hier S. $172 \mathrm{f}$.

28 Wilke: Medien- und Kommunikationsgeschichte (Anm. 6), S. $263 \mathrm{f}$.

29 Zum Einsiedler Marien-Kalender vgl. Brunold-Bigler: Die religiösen Volkskalender (Anm. 12), S. $108 \mathrm{ff}$.

30 Zum Eichsfelder Marien-Kalender vgl. kürzlich Katja Lüthy: Die Zeitschrift. Zur Phänomenologie und Geschichte eines Mediums. Konstanz/München 2013 (Kommunikationswissenschaft), S. 35-108. 
Wie die in Deutschland gedruckten religiösen Kalender generell, ist auch der Regensburger Marien-Kalender noch weitgehend unerforscht. ${ }^{31}$ Seit 1866 vom Verlag Pustet in Regensburg herausgegeben und in seinen Anfängen von Karl Pustet persönlich redigiert, ${ }^{32}$ erlangte er in kurzer Zeit derartige Popularität, dass die Auflage bereits im Verlagskatalog für 1879 mit fast 400.000 beziffert wird. ${ }^{33}$ Für den Erfolg des Unternehmens spricht außerdem die Tatsache, dass der Verlag sich bald in der Lage sah, das Vertriebsnetz des Kalenders durch Filialen in Übersee zu erweitern ${ }^{34}$ und regionale Ausgaben für unterschiedliche Gebiete des deutschsprachigen Raums anzubieten. ${ }^{35}$ Worin nun lagen die Gründe für diesen Erfolg oder, anders gefragt, wie haben wir uns den Regensburger Marien-Kalender vorzustellen, der zwar ungewöhnlich verbreitet war, ansonsten jedoch als durchaus repräsentativ für die deutschsprachigen katholischen Kalender der zweiten Hälfte des 19. Jahrhunderts gelten darf? Konstitutiv für die religiösen Kalender katholischer, wie übrigens auch protestantischer Provenienz sind zunächst die offenkundigen formalen und inhaltlichen Anleihen bei den Kalendern der Aufklärung: Sie gliedern sich meist in ein durch Anekdoten, kurze Gedichte oder nützliche Informationen angereichertes und durch Monatsvignetten illustriertes Kalendarium, einen Informationsteil, der ein Verzeichnis der Märkte und Messen, Umrechnungstabellen für Maße, Gewichte und Währungen, Hinweise zum postalischen Verkehr oder Genealogien europäischer Königshäuser enthält, sowie einen mehr oder weniger umfangreichen Erzählteil, und sie integrieren darüber hinaus Abbildungen sowie Werbeanzeigen. Der Regensburger Marien-Kalender bildet hier keine Ausnahme: Zwar variieren die inhaltliche Gestaltung und das Bildprogramm des Kalendariums innerhalb der einzelnen Jahrgänge, die Kirchenfeste und Hei-

31 Vgl. immerhin den kurzen Beitrag zum Regensburger Marien-Kalender (im Folgenden RMK) von Christine Oßwald: Der Regensburger Marien-Kalender im 19. Jahrhundert. Marias Bote für das katholische Volk. In: C. O. (Hg.): Volkskalender im 19. und 20. Jahrhundert. Zeitweiser, Lesestoff und Notizheft. Begleitband zur Ausstellung im Kreismuseum Walderbach vom 22. Juli bis 31. Oktober 1992. Cham 1992, S. $60-78$.

32 Vgl. Die Firmengeschichte des Verlags Friedrich Pustet Regensburg. Festansprache von Geh. Kommerzienrat Friedrich Pustet zum 100jährigen Gründungsjubiläum beim Festakt am 13. November 1926 im kath. Vereinshause zum hl. Erhard in Regensburg. 2. Aufl. Regensburg 1932, S. 20.

33 Vgl. Oßwald: Regensburger Marien-Kalender (Anm. 31), S. 61.

34 Ab dem Jahrgang 1871 werden als Verlagsorte neu „Regensburg, New York und Cincinnati“ genannt.

35 Vgl. Oßwald: Regensburger Marien-Kalender (Anm. 31), S. 61. 
ligentage, die Wetterregeln des Hundertjährigen Kalenders, die Mondphasen und Planetenerscheinungen sowie die Bauernregeln fehlen jedoch in keinem der frühen Exemplare. Auch mit Blick auf den Erzählteil ist zu konstatieren, dass der Regensburger Marien-Kalender mit der Kalenderlesern vertrauten Mischung aus Anekdoten, Gedichten und vor allem Prosaerzählungen belehrenden und unterhaltenden Charakters aufwartet. Was ihn von seinen säkularen Vorläufern unterscheidet, ist dessen konsequente religiöse Überformung. Dies betrifft zum einen den praktischen Teil, dessen Illustrationen Heilige, Apostel, Szenen aus dem Leben Jesu, Geschichten aus dem Alten Testament, geistliche Embleme sowie ab 1875 eine Serie von Wallfahrtskirchen darstellen, deren jeweils auf eine Marienerscheinung zurückgehende Gründungsgeschichte im Kalendarium berichtet wird. Die konfessionelle Ausrichtung manifestiert sich auch im Erzählteil, der über Vorgänge im Vatikan berichtet, ${ }^{36}$ Lebensbilder katholischer Heiliger und Geistlicher, ${ }^{37}$ Missionsberichte, ${ }^{38}$ Darstellungen von Orden und geistlichen Instituten, ${ }^{39}$ Beschreibungen bedeutender Wallfahrtsdestinationen und Kirchenbauten, ${ }^{40}$ oder eine Darstellung des Oberammergauer Passionsspiels von 1870 bietet. ${ }^{41}$ In so gut wie allen Jahrgängen finden sich außerdem erbauliche Gedichte und Balladen, ${ }^{42}$

36 Vgl. z. B. Erinnerungen an die glorreichen Thaten der päpstlichen Armee im Jahre 1867 (RMK 1869, 47 f.); Beschreibung der Sekundizfeier Papst Pius IX. (RMK 1870, 41-44); Deutschland in Rom beim Papstjubiläum unsers heiligen Vaters Pius IX. (RMK 1872, 30-33); Dem Andenken des lieben heiligen Vaters Pius IX. oder Dem heiligen Vater Leo XIII. zum Gruße! (RMK 1879, 35- 42 sowie 43-50).

37 Vgl. z. B. Maria von Mörl und Erzbischof Hermann von Freiburg (RMK 1869, 38 - 41 sowie $41 \mathrm{f}$. ); Pater Clemens Maria Hoffbauer (RMK 1870, 40 f.); Dr. Nicolaus von Weis, Bischof von Speier (RMK 1871, 33 ff.); Joseph Feßler, Bischof von St. Pölten und Generalsecretär des vaticanischen Concils (RMK 1873, 42f.); P. Maria Alphons Ratisbonne (RMK 1876, 49-54); Der Sänger des schmerzhaften Freitags (Jacopone da Todi; RMK 1877, 79-91); Cardinal Giacomo Antonelli (RMK 1878, $37-40)$.

38 Vgl. z. B. Der Apostel Ohio's, oder Father Fenwick's erste Missionsreise in das innere des OhioGebietes (RMK 1869, 35 f.); Fürst Demetrius Augustin Gallitzin und sein Wirken für die katholische Kirche in Pennsylvanien (RMK 1870, 46 ff.); Die katholischen Missionen (RMK 1875, 98 f.).

39 Vgl. z. B. Die Marien-Anstalt zu Linz (RMK 1874, 40 f.); Die niederdeutsche Ordensprovinz der Redemptoristen und Die Benediktiner-Abtei von St. Martin in Beuron im obern Donauthal (RMK 1877, 127 -134); Das Kloster der Franziskanerinnen zu Kapellen bei Geldern, Das älteste Kloster der Ursulinerinen in Deutschland, Der Franziskaner-Orden in Norddeutschland und Der Ritterorden der hl. Maria von Jerusalem oder der Deutsch-Orden (RMK 1878, 75-94); Gründung der Gesellschaft Jesu (RMK 1879, 59-64 u. 67 f.).

40 Vgl. z. B. Der Dom zu Regensburg und Bilder aus Rom (RMK 1870, 26 f. sowie 28-39); Eine Wallfahrt zu U. L. F. von Lourdes (RMK 1874, 42-47); Maria Laach (RMK 1877, 113-120). 41 Vgl. RMK 1871, 50-53.

42 Vgl. z. B. Vom Vertrauen auf Gott und Oster-Alleluja (RMK 1869, 36 sowie äußeres hinteres Deckblatt); Die Wunder-Apotheke (RMK 1870, 45); Das Waisenhaus (RMK 1871, 36); Die Sanft- 
sowie Psalmen; ${ }^{43}$ ab dem Jahrgang 1872 darüber hinaus ein Zyklus von Graphiken und Gedichten zum Kirchenjahr. ${ }^{44}$ Auch die zunehmend zahlreichen Abbildungen zeigen neben Porträts in erster Linie religiöse Motive: Sie illustrieren zum einen die Erzählungen und Gedichte und fungieren in Form ganzseitiger Darstellungen Mariens, Christi und katholischer Heiliger als Vorlagen für private Andacht. Schließlich ist festzuhalten, dass auch die auf wahren Begebenheiten beruhenden oder fiktiven Beiträge mit primär unterhaltendem Charakter fast durchgängig eine konfessionell gefärbte moralisch-didaktische Grundtendenz aufweisen und sich der religiösen Absicht des Kalenders unterordnen. Die spezifisch marianische Spiritualität, die der Regensburger Marien-Kalenders seinen Adressaten vermitteln will, äußert sich in vielfältiger Weise: So zeigt das Frontispiz des Kalenders Maria als Madonna mit Kind, als schmerzensreiche Mutter am Kreuz Christi sowie und vor allem als Himmelskönigin, und auch im Inneren des Kalenders finden sich wiederholt der traditionellen Ikonographie der Gottesmutter verpflichtete Visualisierungen Mariens. Letztere steht außerdem im Zentrum zahlreicher, in der Regel Text und Bild amalgamierender Beiträge, wie etwa Unsere liebe Frau von der immerwährenden Hilfe in Rom (RMK 1871, $31 \mathrm{f}$.), Geh zu Maria und Das Marienbild (RMK 1873, 33 sowie 47-57), Marianisches Alphabet in Bild und Lied (RMK 1875, 90-95), Die Verbreitung der Ehre Mariens in den Vereinigten Staaten und Die Krönungsfeier U. L. Frau vom Heiligen Herzen am 25. Oktober 1874 in Innsbruck (RMK 1876, 59-63), Das Ave Maria und Maiblumen zu Ehren der Mutter Gottes (RMK 1877, 35-40 sowie 51f.), Das Leben der allerseligsten Jungfrau Maria in 6 Bildern nach den Gesichten der gottseligen Anna Katharina Emmerich, Die Marienerscheinungen in Marpingen oder Marianische Legende (RMK 1878, 47-72).

Der Regensburger Marien-Kalender, daran kann kein Zweifel bestehen, hält, was sein Name verspricht, bietet er seiner Leserschaft doch die Möglichkeit einer noch stärkeren Verankerung im katholischen Glauben sowie einer Vertiefung marianisch geprägter Spiritualität. Nicht weniger offenkundig als der Rekurs auf eine in der Tradition der römisch-katholischen Kirche stehenden Religiosität ist allerdings dessen Bemühen um (konfessions)politische Positionierung und so gehört der insbesondere die in den 1870er Jahren erschienenen Jahrgänge charakterisierende Dualismus von Erbauung und kulturkämpferischem Impetus zu den hervorstechendsten Merkmalen des Regensburger Marien-Kalenders. Dass ein religiöses Periodikum seinen Lesern Erbauliches bietet, überrascht nicht, und

muth (RMK 1872, 62); In Gott (RMK 1874, 41); Die Legende von der heiligen Odilia (RMK 1876, 75 ff.); Wie Gott es will (RMK 1878, 129 f.); Die Erbsen der heiligen Nothburg (RMK 1879, 131f.). 43 Vgl. z. B. Psalm 120. Bei Gott ist Schutz und Hilfe (RMK 1877, 49 f.).

44 Weihnachten (RMK 1872, 26f.); Ostern (RMK 1873, 30f.); Pfingsten (RMK 1874, 30f.); Epiphanie (RMK 1875, 39f.); Christi Himmelfahrt (RMK 1876, 43 f.). 
tatsächlich machen „Reflexionen über die Tages-Heiligen, [...] ,Weckrufe“ an das katholische Volk, kurze moralische Erzählungen, erbauliche Gedichte“ und damit jene für persönliche Andachtsübungen geeigneten religiös-literarischen Gebrauchsformen, die der Herausgeber des Eichsfelder Marien-Kalenders unter dem Begriff ,Erbauung' subsumiert, ${ }^{45}$ einen wesentlichen Teil auch des Regensburger Marien-Kalenders aus. Eine Auffassung von ,Erbauung‘, die ausschließlich deren auf die Anleitung zu individueller Frömmigkeit zielende Intention in den Blick nimmt, greift allerdings gerade im Fall der katholischen Kalender zu kurz, bezeichnet der Begriff ,Erbauung، im Sinne altkirchlicher Autoren doch nicht nur die Aufrichtung der Seele, sondern auch die Vervollkommnung der ecclesia Christi. ${ }^{46}$ Es ist diese zweite Bedeutung, die in der zweiten Hälfte des 19. Jahrhunderts im Kontext einer sich erneuernden katholischen Spiritualität an Bedeutung gewinnt. Der britische Historiker Christopher Clark hat in seinen Studien zum europäischen Kulturkampf als Indikatoren für die von ihm postulierte „religiöse Revitalisierung“ die zahlreichen Kirchenneubauten, die Gründung religiöser Stiftungen und Vereine, der Anstieg der Zahl der Ordensmitglieder, die intensivierte Missionstätigkeit, die Blüte der katholischen Massenpresse und den Geltungsgewinn katholischer Volksfrömmigkeit ausgemacht. ${ }^{47}$ Letztere nun war weniger einem sich eigendynamisch entwickelnden Mentalitätswandel innerhalb der katholischen Bevölkerung geschuldet als vielmehr den systematischen Bestrebungen der römischen Kirche, traditionelle Formen religiöser Observanz wieder auferstehen zu lassen. Das von Papst Pius IX. am 8. Dezember 1854 verkündete Dogma von der unbefleckten Empfängnis Mariens trug wesentlich zur Popularität der Gottesmutter bei, deren Verehrung in der Folge zu einem Kristallisationspunkt katholischer Frömmigkeit avancierte. ${ }^{48}$ Der ebenfalls außerordentlich verbreitete HerzJesu- sowie der Heiligenkult wurden vor allem durch Ordensgeistliche gefördert, ${ }^{49}$ die Ausweitung des Wallfahrts- und Prozessionswesens wiederum verdankte sich primär der Initiative von Bischöfen und Priestern. Ziel der sowohl von Klerikern als auch von Laien getragenen religiösen Erneuerung war die Romanisierung des

45 Vgl. Eichsfelder Marien-Kalender 1887, hinteres äußeres Deckblatt.

46 Zur doppelten Bedeutung von ,Erbauung، vgl. John Procopé/Rudolf Mohr/Hans Wulf: Erbauungsliteratur. In: Gerhard Müller u .a. (Hg.): Theologische Realenzyklopädie. 36 Bde. Berlin/ New York 1977 - 2004, Bd. 10. Berlin/New York 1982, S. 28-83, hier S. 29.

47 Vgl. Clark: Der neue Katholizismus (Anm. 3), S. 14.

48 David Blackbourn spricht in diesem Zusammenhang von einer „Marianization of Catholicism“ (Blackbourn: The Long Nineteenth Century [Anm. 1], S. 299).

49 Vgl. Clark: Der neue Katholizismus (Anm. 3), S. 18. Zum Herz-Jesu-Kult vgl. Norbert Busch: Frömmigkeit als Faktor des katholischen Milieus. Der Kult zum Herzen Jesu. In: Olaf Blaschke/ Frank-Michael Kuhlemann (Hg.): Religion im Kaiserreich. Milieus - Mentalitäten - Krisen. Gütersloh 1996 (Religiöse Kulturen der Moderne 2), S. 136-166. 
Katholizismus, d.h. die Etablierung einer uniformeren, zentralisierteren, stärker auf Rom ausgerichteten Frömmigkeit, in der kirchliche Hierarchie und Basis konvergierten. ${ }^{50}$ Für die Propagierung eines derart wiederbelebten Katholizismus spielten nicht allein kirchliche Institutionen und Akteure, sondern außerdem die konfessionell gebundene Publizistik eine zentrale Rolle. Belege dafür bietet auch und gerade der Regensburger Marien-Kalender, der der Marienverehrung, den Lebensbildern katholischer Heiliger, dem Herz-Jesu-Kult, Wallfahrten und Prozessionen breiten Raum gewährt. Die doppelte Konnotation von ,Erbauung، im Sinne einer spirituellen aedificatio des einzelnen Gläubigen und einer Festigung der Kirche als Gemeinschaft der Frommen kommt zudem in jenen rekurrierenden Erzählungen über Konvertiten und über junge Männer, welche im Priesterberuf ihre Erfüllung finden, zum Tragen, die die Autorität und die Dynamik der katholischen Kirche veranschaulichen und zugleich die geistliche Laufbahn als sinnvollen Lebensentwurf propagieren sollen. ${ }^{51}$

Das erstarkende konfessionelle Selbstbewusstsein der Katholiken steht nun allerdings in scharfem Kontrast zu den Anfechtungen, denen sich die Papstkirche durch den Kulturkampf ausgesetzt sah. Die Herausgeber des Regensburger MarienKalenders werden denn auch nicht müde, die missliche Lage des Kirchenoberhaupts und des katholischen Klerus hervorzuheben. Die Bedrohungslage, in der sich der Pontifex maximus und seine Kirche befänden, wird immer neu beschworen, während die von der intransigenten Haltung Papst Pius IX., namentlich des die Irrtümer der Moderne geißelnden Syllabus Errorum von 1864 und der Verkündigung des Infallibilitätsdogmas anlässlich des ersten Vatikanischen Konzils für Protestanten und liberale Katholiken ausgehende Provokation kaum thematisch wird. Vielmehr beklagt die Pius IX. sowie dem katholischen Klerus gewidmete Lyrik und Prosa das Martyrium des seines Territoriums beraubten Petrusnachfolgers, der als Gefangener des italienischen Staats im Vatikan auszuharren gezwungen ist, ${ }^{52}$ und die Verfolgungen, denen katholische Geistliche aufgrund des ,Kanzelparagraphen' und der Maigesetze von 1873 im Deutschen

50 Vgl. Clark: Der neue Katholizismus (Anm. 3), S. 14.

51 Das Thema der Konversion steht etwa im Zentrum von Aus dem Tagebuche einer Schauspielerin (RMK 1876, 131-138); das Schicksal eines jungen Mannes, der auf Umwegen zur Einsicht gelangt, dass er für den geistlichen Beruf bestimmt ist, gestaltet beispielsweise die Erzählung Das Feldkreuz (RMK 1876, 114-122).

52 Als Beispiele seien hier die Beiträge Beruf zum Priesterthum als Lohn einer Gabe für Pius IX (RMK 1869, 26), Erinnerungen an die glorreichen Thaten der päpstlichen Armee im Jahre 1867 (RMK 1869, 47 f.) oder Pius IX. (RMK 1873, 40 f.) genannt. Besonders plakativ wird das Martyrium des römischen Pontifex maximus in Des Kreuzes Kampf und Sieg (RMK 1876, 71 - 74) thematisiert, einem illustrierten Gedicht, in welchem das Oberhaupt der katholischen Kirche in blasphemisch anmutenden Weise allegorisch mit dem gekreuzigten Jesus in eins gesetzt wird. 
Reich ausgesetzt waren. ${ }^{53}$ Die im Zuge des Kulturkampfs dekretierten Neuerungen, allen voran die Aufhebung der geistlichen Schulaufsicht und die gegen religiöse Orden gerichteten Maßnahmen werden ausführlich diskutiert und verworfen, die aus Mischehen oder einer ausschließlich zivil geschlossenen Ehe resultierenden Schwierigkeiten drastisch vor Augen geführt. ${ }^{54}$ Ausdruck einer spürbaren Politisierung des Regensburger Marien-Kalenders sind darüber hinaus die die Politiker und das Programm der Zentrumspartei thematisierenden Beiträge, in denen die Leitfiguren des politischen Katholizismus als mutige Kämpfer gegen die Bismarck'sche Politik inszeniert werden. ${ }^{55}$ Ebenfalls im Kontext des Kulturkampfs zu verorten sind schließlich die rekurrierenden, auffällig polemischen Invektiven gegen Altkatholiken etwa in der Erzählung Der Vater und sein Kind oder „Rühre meinen Gesalbten nicht an!“ (RMK 1875, 127-144), in der ein frommer Knabe einem liberalen ,Staatspastor' entgegentritt und die Autorität des Papstes verteidigt.

Die Schärfe der Angriffe gegen die Anhänger reformkatholischer Strömungen ist insofern bemerkenswert, als die meisten Beiträge im Regensburger MarienKalender sich einer tendenziell gemäßigten Diktion befleißigen. Ungeachtet der die Darstellung leitenden manichäisch anmutenden Auffassung einer Welt, in der die katholischen Lichtgestalten gottgefälliger Frömmigkeit schließlich im Kampf gegen die von höllischen Mächten getriebenen Ungläubigen obsiegen; ungeachtet einer omnipräsenten, in katholischer Dogmatik gegründeten propaganda fidei; ungeachtet schließlich der dezidierten politischen Stellungnahmen zugunsten des katholischen Zentrums bemühen sich die meisten Autoren, die Leser nicht durch eine allzu aggressive Rhetorik zu irritieren. Dies dürfte wesentlich mit den konfessionspolitischen Intentionen zusammenhängen, in deren Dienst sich der Regensburger Marien-Kalender stellte: Wenn wir als primäre Adressaten religiöser Kalender die Angehörigen der jeweils eigenen Konfessionsgruppe annehmen, können wir mit Blick auf den Regensburger Marien-Kalender festhalten, dass es dessen Herausgebern in erster Linie darum ging, jene Einheit des Kirchenvolks zu befördern, die ein übergeordnetes Ziel der katholischen Erneuerung seit den 1850er Jahren darstellte. Erreicht werden sollte dies weniger im Modus gegen den liberalen Protestantismus gerichteter polemischer Angriffe als vielmehr durch die Vermittlung von Identifikationsmustern, die im Sinne der Kirche adäquates Ver-

53 So etwa Die preußischen Bischöfe als Martyrer für die heilige Sache der Kirche (RMK 1875, 49 64).

54 Zum Thema der Zivilehe vgl. etwa die Erzählung Civil getraut (RMK 1877, 55 - 78).

55 Vgl. z.B. die Jahres-Rundschau (34-39) im Kalender auf das Jahr 1873, in der die Bismarck'sche Politik aus ultramontaner Perspektive eine scharfe Verurteilung, die Arbeit der Zentrumspartei hingegen, deren herausragende Exponenten den Lesern in Porträts vorgestellt werden, eine äußerst positive Würdigung erfährt. 
halten exemplifizierten. Das rührende Vorbild des sich mit der Kirche und deren Oberhaupt solidarisierenden, seinen Glauben auch gegen größte Widerstände verteidigenden Katholiken und das antagonistisch darauf bezogene abschreckende Beispiel des sich von der Kirche und den in ihr verkörperten religiösen Werten abwendenden, den Lockungen liberaler oder sozialdemokratischer Propaganda folgenden und schließlich göttlicher Strafe unterworfenen Verächters des wahren katholischen Glaubens bilden dabei die Angelpunkte jener zahlreichen Erzählungen, mittels derer die Loyalität zum römischen Katholizismus bestärkt oder wiederhergestellt werden sollte. Die wesentlich mit literarischen Mitteln bewerkstelligte Inszenierung der moralischen Überlegenheit jener Geistlichen und Laien, deren Religiosität in einem Katholizismus römischer Observanz verankert erscheint, zielt darauf, die Leser auf das normative Fundament eines ultramontanen Katholizismus einzuschwören und sie so zu einem homogenen, sich durch eine fest umrissene konfessionelle Identität auszeichnenden religiösen Kollektiv zu formen.

\section{III}

Es kann kein Zweifel daran bestehen, dass der Regensburger Marien-Kalender sich seit seiner Gründung und vor allem während der 1870er Jahre gezielt als Sprachrohr eines ultramontanen Positionen verpflichteten Katholizismus gebärdete und sich als Bollwerk gegen liberale Bestrebungen verstand. So konservativ er hinsichtlich seiner Inhalte und der in ihm vertretenen Auffassungen auch anmuten mag, so innovativ erscheinen allerdings die Strategien, mittels derer er sich in einem zunehmend kompetitiven publizistisch-literarischen Marktumfeld zu behaupten wusste. ${ }^{56}$ Neuartig sind etwa Gestaltungselemente wie das farblich abgehobene Verzeichnis der Märkte und Messen, das ab dem Jahrgang 1872 abwechselnd auf meist gelbem bzw. grünem Papier angeboten wurde, oder die Einführung des Spaltendrucks ab dem Jahrgang 1875, der es erlaubte, größere Textmengen zu integrieren, ohne den Kalender in seinem Umfang beträchtlich erweitern und damit verteuern zu müssen. Bemerkenswert sind außerdem das ab dem Jahrgang 1871 eingeführte „Preis-Rebus“, das den Gewinnern hochwertige Lithographien und Stahlstiche sowie Bücher geistlichen Inhalts in Aussicht stellte,

56 In ihrem Literarischen Handweiser zunächst für das katholische Deutschland loben die Herausgeber denn auch den Regensburger Marien-Kalender, „für dessen textuelle u. bildnerische Ausstattg [sic!] die Verlagshdlg [sic!] kein Opfer scheut“ (Franz Hülskamp/Hermann Rump [Hg.]: Literarischer Handweiser zunächst für das katholische Deutschland. 12. Jahrgang, Nr. 14. Münster 1873, Sp. 418f.). 
sowie das ebenfalls auf eine stärkere Kundenbindung zielende beigeheftete, beidseitig beschreibbare Blatt Schieferpergament. ${ }^{57}$ In welchem Maße die gleichermaßen umtriebigen und ideenreichen Herausgeber des Regensburger MarienKalenders ihre Adressaten im Blick behielten, belegen darüber hinaus die Umrechnungstabellen, die bemüht sind, jeweils aktuelle Informationsbedürfnisse zu befriedigen. So findet sich im Jahrgang 1875 ein „Deutscher Reichs-Münz-Rechner“, der über die aufgrund des am 9. Juli 1873 verabschiedeten Münzgesetzes veränderten Währungsverhältnisse im Deutschen Reich informiert. Die Gründung des Weltpostvereins im Jahr 1874 wiederum bietet Anlass für den Abdruck von Tabellen, die über die Postgebühren im internationalen Brief- und Paketverkehr Auskunft geben. ${ }^{58}$ Von entscheidender Bedeutung für die Attraktivität des $R e$ gensburger Marien-Kalenders dürften jedoch vor allem die zunehmend zahlreichen und aufwendigen Abbildungen gewesen sein, die sich die im 19. Jahrhundert neu entwickelten Bilddruckverfahren, allen voran die Xylographie, zu Nutze machen. Nicht nur das Kalendarium, auch der erzählende Teil sind mit Holzstichen durchsetzt; außerdem bietet der Regensburger Marien-Kalender seinen Lesern großformatige Illustrationen wie etwa diejenige des Oberammergauer Passionsspiels von 1870 im Jahrgang 1871, die bereits erwähnten Darstellungen Mariens, Christi und katholischer Heiliger sowie humoristische Bildergeschichten so bedeutender Zeichner wie Wilhelm Busch oder Adolf Oberländer. ${ }^{59} \mathrm{Im}$ Lauf der 1870er Jahre nimmt die Zahl ganzseitiger, teils auf festem Papier reproduzierter Graphiken deutlich zu, ab dem Jahrgang 1883 findet sich in jedem Kalender mindestens ein kolorierter Holzstich. Der Regensburger Marien-Kalender reagiert damit auf den sich abzeichnenden Siegeszug der illustrierten Massenpresse, die in der zweiten Hälfte des 19. Jahrhunderts zunehmende Popularität genoss. Der Rekurs auf Visualisierungen des zu Vermittelnden schien allerdings für die Herausgeber des Regensburger Marien-Kalenders nicht nur deshalb geboten, weil ein derartiges Vorgehen in einem sich modernisierenden publizistisch-literarischen Markt Wettbewerbsvorteile verhieß, sondern auch, weil der heterogene Adressa-

57 Die Neuerung wird mit den Worten kommentiert: „Wir hoffen, daß die Beifügung desselben [Schieferpergament, S. S. T.] von unsern Kalenderkäufern als eine angenehme Verbesserung befunden werden wird und wollen, wenn wir uns nicht getäuscht haben, diese Beigabe in den künftigen Jahrgängen fortsetzen“ (RMK 1879, hinteres äußeres Deckblatt).

58 Vgl. RMK 1877.

59 Vgl. z. B.Wilhelm Buschs Der Wurstdieb (RMK 1869, 55 f.).Von Adolf Oberländer stammen u. a. Die unruhige Nacht (RMK 1873, 78f.), Die beiden Turner auf der Bank mit der beweglichen Lehne (RMK 1874, 78 f.), Münzwanderung (RMK 1875, 155-160), Silhouettenbilder (RMK 1876, 139 142) sowie die sich über mehrere Jahrgänge erstreckende Serie illustrierter Sprichwörter (RMK 1877 ff.). 
tenkreis katholischer Kalender nach einer Präsentationsform verlangte, die geeignet war, ein breites, hinsichtlich seiner sozialen Herkunft und Bildung sowie seines Alters und Geschlechts disparates Publikum anzusprechen. Der systematische Einbezug qualitativ hochwertiger Illustrationen bot deshalb nicht nur einen Kaufanreiz, er erhöhte zugleich die Zugänglichkeit des Regensburger Marien-Kalenders und gewährleistete damit dessen Reichweite.

Die Geschäftstüchtigkeit der Herausgeber des Regensburger Marien-Kalenders erweist sich nicht nur in der Art und Weise, wie sie die Gestaltung eines traditionsreichen Mediums den sich ändernden Erwartungen potentieller Käufer anpassten, sondern auch in den Vermarktungsstrategien, derer sie sich bedienten. So erhielten die Käufer des Regensburger Marien-Kalenders die Möglichkeit, Kunstblätter mit sakralen Sujets, sogenannte ,Prämienbilder', zu deutlich verbilligtem Preis zu beziehen; ${ }^{60}$ außerdem wurden ihnen bei Sammelbestellungen Rabatte eingeräumt. ${ }^{61}$ Über großformatige Anzeigen wurden sie darüber hinaus umfassend über jene Publikationen aus dem Verlag Pustet informiert, die für sie von Interesse sein konnten. Diese Werbeanzeigen nun machen deutlich, dass die Brüder Friedrich und Karl Pustet seit den 1870er Jahren bestrebt waren, das Programm ihres zunächst auf liturgische und kirchenmusikalische Werke spezialisierten Verlagshauses den sich ändernden Rahmenbedingungen anzupassen und Chancen, die ein sich etablierender publizistisch-literarischer Massenmarkt bot, zu nutzen, und sie dokumentieren zugleich, mit welcher Zielstrebigkeit und welchem Erfolg es dem Regensburger Unternehmen gelang, das Feld der seit der Mitte des 19. Jahrhunderts expandierenden populären katholischen Publizistik zu besetzen: Wesentlich beflügelt durch die Resonanz, die der Regensburger MarienKalender insbesondere im Kontext des Kulturkampfs gefunden hatte, initiierten die Brüder Pustet weitere Kalender, die sich nun allerdings weniger an eine tendenziell disparate katholische Leserschaft richteten, sondern vielmehr den Bedürfnissen spezifischer Adressatenkreise entgegenkamen. Dies gilt besonders für den seit 1876 erscheinenden Caecilien Kalender, der, so die Hoffnung des für den Inhalt der Publikation verantwortlich zeichnenden Regensburger Domkapellmeisters Franz Xaver Haberl, bei „Chorregenten, Organisten oder Chorpersonal“ auf ein positives Echo stoßen ${ }^{62}$ und der kirchenmusikalischen Erneuerungsbewegung des Cäcilianismus, die im Verlag Pustet seit längerem eine wichtige Pu-

60 Vgl. die entsprechende Ankündigung in RMK 1875 (hinteres äußeres Deckblatt). Das Angebot wird in den darauffolgenden Jahrgängen wiederholt und erweitert.

61 Vgl. die Ankündigung in RMK 1876, hinteres inneres Deckblatt.

62 Caecilien Kalender für das Schaltjahr 1876. Redigiert zum Besten der kirchlichen Musikschule von Fr. X. Haberl, Domkapellmeister in Regensburg. Druck von Friedrich Pustet in Regensburg, New York und Cincinnati, S. IV. 
blikationsbasis besaß, ${ }^{63}$ Aufwind verschaffen sollte. Auch der zunächst in Innsbruck bei Felix Rauch erscheinende, seit der Mitte der 1880er Jahre vom Verlag Pustet fortgeführte Glöckleins-Kalender für die Terziaren des hl. Vaters Franciscus zielt auf spezifische Rezipienten, namentlich Angehörige des Franziskanerordens bzw. Mitglieder der den Regeln des Heiligen Franziskus verpflichteten Laienbruderschaften. Allerdings betont die Redaktion im ersten Jahrgang, das titelgebende Glöcklein verstehe sich nicht als „Mönchsglöcklein“ und läute keinesfalls nur für Terziaren, es sei vielmehr jedem frommen, an franziskanischer Spiritualität interessierten Katholiken nützlich, „ruft und mahnt [es] doch zu nichts Anderem, als zu wahrem, kernigem Christentum im täglichen Leben und Treiben des Menschen in der Welt, und ein wahrer Christ zu sein muß doch Jeder verlangen, der nicht dem Glauben an den Gekreuzigten entsagt hat."64 Der von Pustet 1873 erstmals aufgelegte Kleine Marien-Kalender für christliche Frauen und Jungfrauen zeugt ebenfalls vom Bestreben, ein komplementäres Kalenderangebot zu generieren, das den vielfältigen Anforderungen, die ein sich stetig diversifizierendes Lesepublikum stellte, gerecht zu werden in der Lage war. Wie der Titel des Periodikums verrät, weist der Kleine Marien-Kalender für christliche Frauen und Jungfrauen hinsichtlich seiner marianischen Ausrichtung Berührungspunkte mit dem $R e$ gensburger Marien-Kalender auf. So bietet bereits der erste Jahrgang neben der Reproduktion und ausführlichen Erläuterung eines kolorierten Gnadenbilds Mariens $^{65}$ einen Beitrag über Unsere Liebe Frau, und auch in den späteren Jahrgängen finden sich immer wieder geistliche Auslegungen der Muttergottes, Marienlyrik sowie xylographische Farbdrucke, in denen Maria in unterschiedlicher Ikonographie dargestellt erscheint. Ein zweites wesentliches Element des in der Nachfolge der um 1800 vor allem für eine weibliche Leserschaft gedachten Almanache stehenden Kalenders ${ }^{66}$ bilden jene Erzählungen und Betrachtungen, in

63 Vgl. Andreas Jobst: Pressegeschichte Regensburgs von der Revolution 1848/49 bis in die Anfänge der Bundesrepublik Deutschland. Regensburg 2002 (Regensburger Studien 5), S. 56. 64 Glöckleins-Kalender für die Terziaren des hl. Vaters Franciscus. Herausgegeben von der Redaktion des St. Francisci Glöcklein. 1. Jahrgang 1884. Innsbruck. Druck und Verlag von Fel. Rauch, S. 17.

65 Vgl. im Kleinen Marien-Kalender (im Folgenden KMK) Das Gnadenbild genannt: Maria Unsere Liebe Frau von der immerwährenden Hilfe zu Rom (KMK 1873, 20-50). Der Beitrag über Unsere Liebe Frau findet sich in KMK 1873, 51-74.

66 Zum Typus des Almanachs vgl. Wolfgang Bunzel: Almanache und Taschenbücher. In: Ernst Fischer/Wilhelm Haefs/York-Gothard Mix (Hg.): Von Almanach bis Zeitung. Ein Handbuch der Medien in Deutschland 1700-1800. München 1999, S. 24-35 [dort weitere Literatur]. Dafür, dass der Kleine Marien-Kalender für christliche Frauen und Jungfrauen weniger in der Tradition volkstümlicher Kalender als vielmehr in derjenigen des Almanachs steht, sprechen neben inhaltlichen Aspekten das kleinere Format, die sorgfältige Gestaltung, die geringe Bedeutung, die 
denen Idealentwürfe weiblicher Sozialisation mitsamt dem diesen inhärenten Normensystem vor Augen geführt werden. Repräsentativ ist in diesem Zusammenhang der sich über mehrere Jahrgänge erstreckende, mit „Frauenspiegel“ überschriebene Zyklus kurzer Erzählungen, in denen typische Rollenmuster für Mädchen und Frauen narrativ entfaltet werden. ${ }^{67}$ Dass in der Folge außerdem vermehrt Kurzbiographien historisch bedeutender Frauen sowie auf weibliche Lebenswelten bezogene, primär der Information dienende Beiträge integriert wurden, ${ }^{68}$ ändert nichts an der grundsätzlich erbaulichen Ausrichtung einer Veröffentlichung, die sich explizit an ein bürgerliches weibliches Publikum wandte, dem geistlicher Beistand und eine katholisch fundierte Individual- und Sozialethik vermittelt werden sollten.

Nicht nur im Bereich der Kalenderpublizistik, auch auf dem Feld der Familienzeitschriften war der Verlag Pustet darum bemüht, einen an Bedeutung gewinnenden Markt zu erobern. Der enorme Erfolg der Gartenlaube, deren Auflage sich bis 1875 auf 382.000 Exemplare steigerte, ${ }^{69}$ dürfte den wesentlichen Ansporn zur Gründung des Deutschen Hausschatzes gegeben haben, der bereits im ersten Jahr seines Erscheinens 40.000 Abonnenten zu gewinnen vermochte. ${ }^{70}$ Es waren nicht allein pekuniäre Überlegungen, welche die Brüder Pustet dazu bewogen,

dem Kalendarium beigemessen wird, das im ersten Jahrgang fehlt, sowie die verschiedenen Ausführungen, die der Verlag anbot: Die Leserinnen konnten wählen zwischen einer preiswerten und einer aufwendigeren Ausgabe, die auf der Rückseite des Titelblatts des dritten Jahrgangs 1875 mit den Worten angepriesen wird: „In schön Chagrin gebunden mit reicher Deckenverzierung kostet dieser Kalender 1 Mark 80 Pf.“

67 Vgl. KMK, 75 -110. Die Titel der Erzählungen lauten Die brave Tochter, Die kluge Braut, Die treue Gattin, Die liebende Mutter, Die edle Schwester, Die fleißige Wittwe, Die aufopfernde Dienerin, sowie Die Braut des Herm.

68 Vgl. beispielsweise den Beitrag Unsere warmen Getränke (KMK 1878, 183 -191), in welchem die Autorin sich zu Kaffee, Schokolade und Tee äußert, oder die unter dem Titel Die Kleidung der Frauen versammelten kulturhistorischen Ausführungen zur Geschichte verschiedener weiblicher Kleidungsstücke (KMK 1882, 133 -178).

69 Vgl. Wilke: Medien- und Kommunikationsgeschichte (Anm. 6), S. 277.

70 Vgl. den Hinweis am Ende der 26. Nummer des Jahrgangs 1874/75, wo es heißt: „Mit dieser Nummer schließt der Deutsche Hausschatz, 40.000 Abonnenten zählend, sein erstes Halbjahr“ (S. 416). Es scheint zunächst nicht gelungen zu sein, die Abonnentenzahlen noch deutlich zu steigern. Ab den späten 1870er Jahren pendelte sich die Zahl der Abonnenten bei etwa 25.000 ein, bevor sich um die Mitte der 1880er Jahre ein weiterer Rückgang der Absatzzahlen abzeichnete (vgl. Jobst: Pressegeschichte Regensburgs [Anm. 63], S. 309). Unter den Nachfolgern von Venanz Müller entwickelte sich das Blatt dann allerdings zur verbreitetsten katholischen Familienzeitschrift (vgl. Jobst: Pressegeschichte Regensburgs [Anm. 63], S. 87). Auf die Vorbildfunktion der Gartenlaube für den Deutschen Hausschatz weist Sigfrid Färber: Die Pustet und ihr Verlagswerk. In: Verhandlungen des Historischen Vereins für Oberpfalz und Regensburg 117 (1977), S. 289 - 298, hier S. 295, hin. 
eine Familienzeitschrift ins Leben zu rufen, wie der verantwortliche Redakteur Venanz Müller in der ersten Nummer deutlich macht, wenn er die Notwendigkeit einer katholischen Alternative zur liberalen Positionen zuneigenden Gartenlaube hervorhebt:

\begin{abstract}
Seit Jahrzehnten ist von den deutschen Katholiken der Mangel eines illustrirten Unterhaltungsblattes von dem äußeren Umfang, der literarischen Bedeutung, künstlerischen Ausstattung und raschen Erscheinungsweise, wie sie mehreren ausgesprochenen Organen unserer Gegner eigen sind, tief und immer tiefer empfunden worden. Und während katholischerseits das politische Zeitungswesen einen mächtigen Aufschwung nahm, blieb das belletristische Gebiet spärlich angebaut und die Befriedigung des Bedürfnisses nach einer illustrirten Zeitschrift ersten Ranges schien sich von Jahr zu Jahr in unabsehbarer Ferne zu verlieren. Das war doch nachgerade schier als eine Art geistigen Armuthszeugnisses anzusehen und konnte nicht länger ertragen werden. So reifte denn der Entschluß zur Gründung eines illustrirten Central-Organs für wahrhaft sittliche Unterhaltung und volksthümliche Belehrung. Das Projekt ward dem heiligen Vater, Papst Pius IX., ehrfurchtsvoll unterbreitet und von Seiner Heiligkeit [...] gut geheißen [...]. Jetzt aber ist der Entschluß eine That geworden. Die erste Nummer der neuen Wochenschrift: Deutscher Hausschatz in Wort und Bild tritt hiermit in die Welt, gastliche Aufnahme allenthalben suchend, wo christlicher Glaube und christliche Sitte wohnen. ${ }^{71}$
\end{abstract}

Ungeachtet der konfessionspolitischen Ziele, die sich mit dem Deutschen Haus$s c h a t z$ verbanden, bot die Herausgabe eines unbestritten äußerst populären Mediums attraktive ökonomische Perspektiven. Die Herausgeber des Deutschen Hausschatzes waren denn auch bestrebt, das Erfolgsrezept der Gartenlaube zu kopieren; zugleich jedoch setzten sie eigene Akzente, nicht nur indem sie die Verankerung des wöchentlich erscheinenden Periodikums in einer dezidiert römischen Katholizität immer neu zum Ausdruck brachten, sondern indem sie außerdem ein noch vielfältigeres inhaltliches Konzept verfolgten, als es die Gartenlaube ihren Lesern bot, und besonderen Wert auf die Qualität der Illustrationen legten. ${ }^{72}$

71 Deutscher Hausschatz in Wort und Bild. Erster Jahrgang. Verlag von Fr. Pustet. Regensburg, New York \& Cincinnati 1874, S. 1 f.

72 Vgl. die programmatische Äußerungen des Redakteurs in der ersten Nummer des Organs: „Der Deutsche Hausschatz wird anziehende, sittliche Unterhaltung und allgemein nützliche Belehrung verbreiten und so an der Förderung der Volksbildung mitwirken. Einen großen Theil seines Inhaltes bilden neben Gedichten vorzüglich Romane und Novellen. In den Kreis der HausschatzErzählungen gehört Alles, was eine Menschenbrust bewegt, natürlich in poetischer Gestaltung, mit christlich-ethischem Grundton und selbstverständlich mit strengster Abweisung dessen, was das sittliche und religiöse Gefühl verletzt. [...] Der belehrende Teil des Hausschatzes nimmt seinen Stoff aus allen Gebieten des Wissens, der Kunst und des Lebens überhaupt. Da, wo es nöthig scheint, werden Illustrationen den Text begleiten. Unsere Zeit ist die Epoche des materiellen 
Die Herausgeber des Deutschen Hausschatzes haben dessen Popularität nicht nur durch das für die illustrierten Familienblätter des 19. Jahrhunderts konstitutive inhaltliche „Allerlei“ zu gewährleisten versucht, sondern außerdem auf jene strategischen Maßnahmen zurückgegriffen, mittels welcher sie auch anderen im Verlag Pustet erscheinenden Periodika, seien es nun Zeitungen, ${ }^{73}$ Zeitschriften oder Kalender, zum publizistischen Erfolg zu verhelfen gewillt waren und die es nachfolgend noch einmal knapp zu bündeln gilt: Zum einen knüpften die Brüder Pustet bewusst an die Tradition ihres Unternehmens an, das sich einen Namen als führender Verlag für liturgische Drucke sowie Werke katechetischen, dogmatischen, homiletischen, moral- und pastoraltheologischen, hagiographischen und kirchenhistorischen Charakters gemacht hatte. Die dezidiert katholische Programmatik der populären Publizistik gewann ihre hohe Glaubwürdigkeit wesentlich dadurch, dass sie in Einklang stand mit einem Verlagsprofil, zu dessen Markenzeichen theologische Kompetenz und die offensiv kommunizierte konfessionelle Prägung zählten. Zum anderen nutzten die Brüder Pustet ihre guten Beziehungen zu kirchlichen Würdenträgern und Institutionen, um ihre Verlagsproduktion mit dem Gütesiegel päpstlicher Autorisierung zu versehen und die durch den Klerus ${ }^{74}$ sowie das katholische Vereinswesen ${ }^{75}$ eröffneten Absatzkanäle

Fortschrittes. Der Hausschatz schildert also auch hie und da die erstaunlichen Leistungen der Technik und Industrie und widmet den materiellen Interessen die gebührende Beachtung. Daran reihen sich zeitweilig Belehrungen über Gesundheits- und Krankenpflege. Der Hausschatz wird ferner die wichtigeren Begebenheiten auf der Weltbühne verzeichnen und die Lebensbilder von hervorragenden Zeitgenossen vorführen. Auch periodische Berichte aus der Hauptstadt der Christenheit und aus anderen Weltstädten passen in den Rahmen dieses Unterhaltungsblattes, unter dessen auserlesenem „Allerlei“ sogar die nun einmal unvermeidlichen Knackmandeln, Räthsel, Rösselsprünge, Schachaufgaben et hoc genus omne nicht fehlen dürfen. Die Wahl des Bilderschmuckes geschieht auf das Sorgfältigste in Harmonie mit Schönheit und Sittlichkeit. Sowohl die besten Erzeugnisse im Fache der jetzigen deutschen Genremalerei als auch berühmte Werke alter Meister werden wir in trefflichen Holzschnitten zur Anschauung bringen, um den Kunstgeschmack im Volke läutern zu helfen. Das ist nun so ziemlich unser Programm“ (Deutscher Hausschatz [Anm. 71]., S. 2).

$73 \mathrm{Zu}$ den im Verlag Pustet erschienenen Zeitungen vgl. Jobst: Pressegeschichte Regensburgs (Anm. 63), passim.

74 Zur Bedeutung der katholischen Priester für die konfessionsgebundene Schriftkultur und deren Vermittlung an breitere Leserschichten vgl. Olaf Blaschke: Die Kolonialisierung der Laienwelt. Priester als Milieumanager und die Kanäle klerikaler Kuratel. In: O. B./Frank-Michael Kuhlemann (Hg.): Religion im Kaiserreich. Milieus - Mentalitäten - Krisen. Gütersloh 1996 (Religiöse Kulturen der Moderne 2), S. 93-135, hier S. 118-129.

75 Zum katholischen Vereinswesen vgl. Josef Mooser: Das katholische Milieu in der bürgerlichen Gesellschaft. Zum Vereinswesen des Katholizismus im späten Deutschen Kaiserreich. In: Olaf Blaschke/Frank-Michael Kuhlemann (Hg.): Religion im Kaiserreich. Milieus - Mentalitäten Krisen. Gütersloh 1996 (Religiöse Kulturen der Moderne 2), S. 59-92. 
in Anspruch zu nehmen. Die enge Kooperation mit Rom, die Friedrich Pustet 1862 den Titel „Typograph des heiligen Apostolischen Stuhles und der Congregationen der heiligen Riten und Indulgenzen“76 sowie 1864 die Ernennung zum Ritter des Gregoriusordens ${ }^{77}$ eintrug, entsprach einem auch persönlichen Wunsch der Verleger, die sich als fromme Christen und Exponenten eines ultramontan geprägten politischen Katholizismus engagierten; ${ }^{78}$ sie dürfte sich jedoch auch als äußerst vorteilhaftes Vermarktungsinstrument erwiesen haben und macht deutlich, in welchem Maße Frömmigkeit und Geschäftssinn im Falle der Brüder Pustet konvergierten. Vor allem jedoch und drittens erkannten diese früh die Synergieeffekte, die sich aus einem gleichermaßen um einen ,Markenkern' zentrierten und ausdifferenzierten Verlagsprogramm ergaben und wussten sie in den Dienst wirtschaftlicher Handlungsmodi zu stellen, die in ihrer Gesamtheit bemerkenswert modern erscheinen. Das von den Brüdern Pustet geschaffene Gefüge sich ergänzender populärer Publizistik bot erstens eine ideale Werbeplattform, erreichte ein massenhaft verbreitetes Medium wie der Regensburger Marien-Kalender doch zahlreiche Leserinnen und Leser, denen weitere Verlagspublikationen nahe gebracht werden konnten. So wendet sich der Verlag 1875 in einer prominent platzierten ganzseitigen Anzeige an die Leser des Regensburger Marien-Kalenders, um ihnen den Deutschen Hausschatz zu empfehlen, ${ }^{79}$ und in den Folgejahren finden sich im Regensburger Marien-Kalender - wie übrigens auch im Kleinen MarienKalender für christliche Frauen und Jungfrauen - immer wieder großformatige Anzeigen, die für das Familienblatt werben. Umgekehrt diente auch der Deutsche Hausschatz als Multiplikator nicht nur der Buch-, sondern auch der Kalenderproduktion des Regensburger Unternehmens, wie zahlreiche für die beiden vorgenannten Kalender werbende Anzeigen belegen. Von Vorteil dürfte zweitens gewesen sein, dass die im Bereich der Herstellung graphischer Serien und Einzelblätter erworbene Expertise, die langjährigen Geschäftsbeziehungen zu Künstlern ${ }^{80}$ und die dem Verlag verfügbaren technischen Infrastrukturen es er-

76 Jobst: Pressegeschichte Regensburgs (Anm. 63), S. 56.

77 Vgl. Otto Denk: Friedrich Pustet, Vater und Sohn. Zwei Lebensbilder, zugleich eine Geschichte des Hauses Pustet. Regensburg u.a. 1904, S. 88.

78 Zum kirchlichen und politischen Engagement insbesondere Friedrich Pustets vgl. Jobst: Pressegeschichte Regensburgs (Anm. 63), S. 55 ff.

79 Vgl. RMK 1875, vorderes inneres Deckblatt.

$80 \mathrm{Zu}$ nennen wäre hier etwa der Kirchenmaler Max Schmalzl, der im Rahmen seiner sich über mehrere Jahrzehnte erstreckenden Zusammenarbeit mit dem Verlag Pustet eine Reihe von Illustrationen für den Regensburger Marien-Kalender geschaffen hat (vgl. Monika SchwarzenbergerWurster: Frater Max Schmalzl (1850-1930). Katholische Bildpropaganda in der christlichen Kunst des späten 19. Jahrhunderts. Monographie und Werkkatalog. Diss. Universität Regensburg 2010, S. 236 - 262 [urn:nbn:de:bvb:355-epub-153010; letzter Zugriff 15. Mai 2015]). 
laubten, den für den Erfolg populärer Medien unabdingbaren Bilderreichtum zu generieren und ihn, etwa indem ein Entwurf mehrfach Verwendung fand, ${ }^{81}$ ökonomisch zu organisieren. Drittens profitierten Verlag und Autoren von der für die belletristische Produktion des 19. Jahrhunderts konstitutiven symbiotischen Beziehung zwischen Zeitschriftenwesen und Buchmarkt. Kalender und Familienzeitschrift boten Autoren die Möglichkeit, sich einem breiteren Publikum zu präsentieren; der Verlag wiederum erreichte, indem er namhafte Schriftsteller unter Vertrag nahm und deren Werke zunächst in Fortsetzungen abdruckte, um sie dann als Volksausgabe auf den Markt zu bringen, eine stärkere Leserbindung, höhere Auflagenzahlen und zusätzliche Gewinne. Bedeutende Exponenten einer konfessionell gefärbten Belletristik wie etwa Conrad von Bolanden [i. e. Joseph Eduard Konrad Bischoff] oder Franz von Seeburg [i. e. Franz Xaver Hacker] spielen denn auch nicht nur in den unterhaltenden Periodika, sondern auch im Literaturprogramm des Verlags Pustet eine zentrale Rolle. Das Zusammenspiel unterschiedlicher Medien bot viertens Raum für die Erprobung innovativer Ideen, die den Erfolg der Unternehmungen in einem äußerst kompetitiven Marktumfeld sichern sollten. So dürfte, um nur ein Beispiel zu nennen, das positive Echo auf die Einführung eines Preisrätsels und die Beigabe von Anzeigenbeilagen im Regensburger Marien-Kalender die Brüder Pustet dazu bewogen haben, im Deutschen Hausschatz Vergleichbares zu bieten; umgekehrt konnte, was sich in der Familienzeitschrift bewährt hatte, in den Kalender Eingang finden. Schließlich und fünftens verbesserte sich durch die Erweiterung des Geschäftsfeldes die Auslastung der technischen Infrastruktur. Für einen Verlag, der seit den 1860er Jahren über eine der leistungsstärksten Druckereien Süddeutschlands verfügte ${ }^{82}$ und im Besitz einer eigenen, hochmodernen Papierfabrik war, ${ }^{83}$ dürfte dies durchaus von Bedeutung gewesen sein.

Wenn Michael Schmolke dem Katholizismus im hier interessierenden Zeitraum ein „gebrochenes Verhältnis“ zur Publizistik im Verbund mit einem „wenig herzhaften Verhältnis zur kapitalistischen Ökonomie“ attestiert, ${ }^{84}$ erscheint dies

81 Dies gilt beispielsweise für die Abbildung Unserer lieben Frau von der immerwährenden Hilfe in Rom, die sowohl im Regensburger Marien-Kalender (RMK 1871, 31 f.) als auch - nun in Form einer kolorierten Xylographie - im Kleinen Marien-Kalender für christliche Frauen und Jungfrauen (KMK 1873, 20) begegnet.

82 Jobst: Pressegeschichte Regensburgs (Anm. 63), S. $56 \mathrm{f}$.

83 Vgl. [Elisabeth Pustet]: Pustet. Das Buch. Ein bayerisches Unternehmen. [Regensburg 2014], S. $32 \mathrm{f}$.

84 Michael Schmolke: Katholisches Verlags-, Bücherei- und Zeitschriftenwesen. In: Anton Rauscher (Hg.): Katholizismus, Bildung und Wissenschaft im 19. und 20. Jahrhundert. Paderborn 1987 (Beiträge zur Katholizismusforschung), S. 93-117, hier S. 94. 
angesichts der Souveränität, mit der das Unternehmen Pustet religiös fundierten Konservatismus und moderne Geschäftspraktiken zu harmonisieren wusste, durchaus fragwürdig. Wie der ebenfalls in Regensburg tätige Verlag Manz oder jener des Donauwörther Pädagogen Ludwig Auer belegen, waren die Brüder keinesfalls die einzigen katholischen Verleger in Bayern, denen es seit der Mitte des 19. Jahrhunderts gelang, sich erfolgreich neuen Marktbedingungen anzupassen und mit ihrer dem Dreiklang von Erbauung, Unterhaltung und Politik verpflichteten publizistischen Produktion jenem Ideal gerecht $\mathrm{zu}$ werden, das der aus dem Bistum Regensburg gebürtige Priester und Schriftsteller Andreas Niedermayer in einer 1861 anonym erschienenen Schrift mit dem Titel Die katholische Presse Deutschlands formuliert hatte. In Anbetracht der Angriffe, denen sich die Katholiken durch die liberale Presse ausgesetzt sähen, müssten die romtreuen Christen, so der Autor, „von den Feinden lernen“ ${ }^{\text {“5 }}$ und „die Circulationsmittel und die mächtigsten Triebfedern der modernen Gesellschaft sich tributbar machen“, 86 zu denen Niedermayer in erster Linie die Presse zählt. ${ }^{87}$ Niedermayer belässt es nicht mit einem Appell, die Möglichkeiten, welche ein sich professionalisierendes Publikationswesen böten, zu nutzen, er konkretisiert die zu ergreifenden Maßnahmen, beklagt in diesem Zusammenhang den Mangel an katholischen Journalen nach dem Muster der Gartenlaube, der Leipziger Illustrirten Zeitung oder der Zeitschrift Über Land und Meer und fordert eine katholische populäre Publizistik, welche die Leser nicht dem „grundlose[n] papierne[n] Meer“ all der „flachen Romane, seichten Schauspiele, phantasielosen Märchen, Almanache, Taschenbücher, Journale und Tageblätter“ überlasse, die mangels Alternativen auch in katholischen Kreisen Verbreitung gefunden hätten, ${ }^{88}$ sondern sie auf erbauliche und zugleich ästhetisch anspruchsvolle Weise unterhalte. Als nachahmenswerte Beispiele katholischer Volksschrifttums führt Niedermayer übrigens einige Kalender ins Feld, namentlich Adolph Kolpings Kalender für das katholische Volk, Alban Stolz' Kalender für Zeit und Ewigkeit für das gemeine Volk und nebenher für geistliche und weltliche Herrenleute oder den auch in Deutschland verbreiteten Einsiedler Kalender, ${ }^{89}$ verkörpern diese in seinen Augen doch eine gelungene Synthese zwischen katholischer Programmatik und zeitgemäßer Diktion und

85 [Andreas Niedermayer]: Die katholische Presse Deutschlands. Freiburg/Br. 1861, S. 7.

86 Niedermayer: Die katholische Presse (Anm. 85), S. 8.

87 Vgl. Niedermayer: Die katholische Presse (Anm. 85), S. 6, wo er die Presse als eine Sprache beschreibt, „die stärker tönt als die gewöhnliche Sprache; die Dampfkraft und die Electricität stehen in ihrem Dienste, mit Sturmeseile und Blitzesschnelle gehen die Reproductionen des Gedankens durch die ganze Welt“.

88 Niedermayer: Die katholische Presse (Anm. 85), S. 50.

89 Niedermayer: Die katholische Presse (Anm. 85), S. 52. 
machten darüber hinaus deutlich, welchen Einfluss Priester gewinnen könnten, wenn sie sich publizistisch betätigen. Niedermayer plädiert denn auch für eine aktive Rolle der Geistlichkeit und erinnert daran, dass die „Publicisten berufen [seien], die Kerntruppen der Wahrheit und der Freiheit zu sein“. ${ }^{90}$ Die Kirche, so Niedermayers Fazit, solle die Presse nicht perhorreszieren, sondern sich vielmehr darauf besinnen, dass sie eine „katholische“ sei und „auch in den Mitteln zur Erreichung ihrer Bestimmung universal“;”1 sie solle sich mit jenen „Buchhändlern, die sich als wahrhaft katholische ausweisen“ verbinden, „sie mit Rath und That [...] unterstützen und durch ein offenes, planmäßiges Zusammenwirken mit ihnen die Literatur in großartiger Weise zu heben“ versuchen. ${ }^{92}$ In einer Zeit, „da die Industrie das Unglaublichste erzielt, ein unermeßlicher Verkehr den Planeten umgestaltet und die Weltgeschichte mit Riesenschritten vorangeht"93 bedürfe es dazu selbstverständlich all jener Instrumente, welche einem Verleger zu Dienste stünden.

Wie der Aufschwung der katholischen Presse in der zweiten Hälfte des 19. Jahrhunderts zeigt, verhallte der Ruf nach einer zeitgemäßen konfessionsgebundenen Publizistik, welche die Bedürfnisse eines rasant wachsenden Lesepublikums in ihrem Sinne nutzt, statt sie zu verurteilen, nicht ungehört. Wie auch andere katholische Verleger waren die Brüder Pustet seit den 1860er Jahren bestrebt, das Feld der massentauglichen Publizistik systematisch zu besetzen, indem sie Kalender und Familienzeitschriften gründeten, Volksausgaben konfessionell gefärbter Belletristik veröffentlichten, das Angebot an Predigt- und Gebetsbüchern, Heiligen- und Legendensammlungen erweiterten, die Herstellung und den Vertrieb religiöser Druckgraphik forcierten und sich damit als eines der kommerziell erfolgreichsten katholischen Verlagshäuser zu etablieren vermochten. So traditionsorientiert die Ideen auch anmuten mögen, die das Regensburger Unternehmen - oft mit päpstlicher Lizenz und immer unterstützt von publizistisch engagierten Angehörigen des Klerus - unter das Kirchenvolk brachte, so zeitgemäß wirken die Praktiken, mittels derer es katholisches Gedankengut popularisierte. Die populäre Publizistik aus dem Hause Pustet bietet denn auch ein besonders interessantes Beispiel für jene Synthese von Konservatismus und ökonomisch motivierter Modernität, die zu den bemerkenswertesten Befunden der Analyse des katholischen Pressewesens im mittleren 19. Jahrhundert zählt.

90 Niedermayer: Die katholische Presse (Anm. 85), S. 56.

91 Niedermayer: Die katholische Presse (Anm. 85), S. 59.

92 Niedermayer: Die katholische Presse (Anm. 85), S. 68.

93 Niedermayer: Die katholische Presse (Anm. 85), S. 70. 
